\title{
Balance performance in sedentary and active healthy young individuals - a cross-sectional study
}

Radu Petroman ${ }^{\mathrm{ABDE}}$, Andreea Luciana Rață ${ }^{\mathrm{ACDE}}$

"Victor Babes" University of Medicine and Pharmacy Timisoara, Romania

Authors' Contribution: A - Study design; B - Data collection; C - Statistical analysis; D - Manuscript Preparation; E - Funds Collection.

\begin{abstract}
Purpose: $\quad$ Balance ability has a fundamental role in many activities of daily living, as well in athletic activities. The Balance Error Scoring System is a valid and reliable test used to evaluate postural balance. The aim of this study was to assess the postural balance in active and sedentary healthy young individuals.

Material: $\quad$ A cross-sectional study was carried out to evaluate the balance performance in forty-four healthy young individuals (mean age $21.69 \pm 4.87$ years), based on their physical activity level. Balance was assessed using the Balance Error Scoring System (BESS), and the total number of errors was scored, for the non-dominant limb (the left leg for both groups). The errors were counted for each of the six situations (double leg stance, single leg stance and tandem stance, on hard and soft surface).

Results: $\quad$ Group 1 consisted of twenty-two active subjects (mean age $21.18 \pm 2.32$ years, 59.09\% females), with a BESS score of $9.87 \pm 1.6$. The sedentary group (group 2 ), with twenty-two young subjects (mean age $22.22 \pm 6.61$ years, $59.09 \%$ females), scored a significantly higher BESS score for the sedentary group (15.48 \pm 2.24$)$ $(p<0.001)$. No gender differences were recorded.

Conclusions: Physically active young people have a better postural balance than do the sedentary ones, as scored with the BESS.

Keywords: $\quad$ balance, physical activity, Balance Error Scoring System, young individuals.
\end{abstract}

\section{Introduction}

Balance is defined as an ability to maintain a stable base of support in either static or dynamic conditions $[1,2]$. Both static and dynamic balance abilities have a fundamental role in many activities of daily living, as well in athletic activities. Impaired balance is a risk factor for sports-related injuries or falls across life span [3]. There are different tests commonly used to assess static and dynamic balance as a screening method to identify athletes at risk of lower limb injuries $[4,5]$ or people with an increased risk of falls. Balance tests can be applied in order to diagnose different conditions or to evaluate the rehabilitation outcomes $[1,6]$.

Physical activity has a crucial role in providing an independent healthy life, maintaining postural stability [7], mobility, strength [8], and normal weight, preventing falls and injuries, and protecting against the cardiovascular diseases [9, 10] and stroke [11]. Although the physical activity benefits are well known, there is a relative high percentage of young adults characterized by a sedentary behaviour $[12,13]$. Previous studies have showed that physical inactivity is associated with overweight and obesity and high psychological distress [14, 15].

To our knowledge there are only few studies evaluating the effects of being physically active on postural balance in healthy young adults. Many studies have focused on the effect of exercise and physical activity on balance in older individuals. Based on the data found in the literature, we hypothesised that the physically active young people will

\footnotetext{
(c) Radu Petroman, Andreea Luciana Rață, 2020
}

doi:10.15561/20755279.2020.0207 have a better postural balance than the sedentary ones.

The aim of this study was to assess the static balance performance of healthy young individuals related to their level of physical activity.

\section{Material and methods}

Participants

A cross-sectional design was adopted to evaluate the balance performance in healthy young individuals based on their physical activity level. The study was carried out in accordance with the Declaration of Helsinki.

A convenience sample of forty-four healthy young individuals (mean age $21.69 \pm 4.87$ years) was recruited. Participants were excluded from this study if they had a history of lower limb injuries or surgery, concussion, vestibular or neurological disorders or were not currently experiencing any symptoms that could affect their postural control. All participants who met the inclusion criteria and agreed to participate signed an informed consent. Before balance testing, participants' demographic data were collected - age, sex, weight, height, body mass index, dominant leg (preferred kicking leg) [16].

Procedure

Participants were assigned into two groups (sedentary and physical active), according to the International Physical Activity Questionnaire (IPAQ) - short form. Physical active participants (group 1) were considered those who conduct five or more days a week of moderateintensity physical activity, for at least 30 minutes per session, or at least three days of vigorous physical activity for at least 20 minutes per session. In the sedentary group 
were assigned subjects with no physical activity during the week (group 2) [17, 18].

Balance performance was assessed using the Balance Error Scoring System (BESS). The BESS protocol [19] requires the participants to complete six testing conditions - three stances (double leg, single leg and tandem stance) on both firm and foam surfaces. The nondominant foot was tested. Participants were instructed to place their hands on the hips, eyes closed and to maintain their stability in that position for 20 seconds. The feet position was side-by-side in the double leg stance; standing on the non-dominant foot in single leg stance; and heel-to-toe with the non-dominant foot in the back. The number of errors was counted for each condition. An error was considered if the participants moved the hands off the iliac crests, opened the eyes, stepped stumble or fell, moved the hip (abduction or flexion beyond $30^{\circ}$ ), lifted the forefoot or the heel of the testing surface, remained out of proper testing position for more than 5 seconds. For any single condition, the maximum number of errors was 10. The total BESS score is the sum of each stance position scores. A higher total score represents a poor performance. The participants completed three trials for each BESS condition and an average score was calculated.

Statistical analysis

Statistical analysis was performed using MedCalc
(Software bvba, Belgium, version 18.11.6). Descriptive statistics were used to describe the participants' data and the BESS scores (means and standard deviations, median and interquartile range for non-normal distributed data). Mann Whitney tests and independent $t$-tests were used to compare BESS scores between groups. Significance level was set at .05 .

\section{Results}

Group 1 consisted of twenty-two active young subjects (mean age $21.18 \pm 2.32$ years, $59.09 \%$ females). The sedentary group (group 2) consisted of twenty-two young subjects (mean age 22.22 \pm 6.61 years, 59.09\% females). All subjects were normal-weighted with no significant differences between groups (BMI for group 1 was $22.51 \pm 2.24 \mathrm{~kg} / \mathrm{m}^{2}$ and for group $2,20.88 \pm 2.41 \mathrm{~kg} /$ $\mathrm{m}^{2}$ ).

The total BESS score was $9.87 \pm 1.6$ for group 1 and $15.48 \pm 2.24$ for group 2. The sedentary group scored significantly higher than the physically active group $(p<0.001)$. Significant differences between groups were also found for bipodal stance and tandem stance on the foam surface $(p<0.01)$. The results of BESS scores are presented in Table 1

No significant gender differences were found for any of the assessed testing conditions.

Table 1. BESS scores for both groups

\begin{tabular}{llll}
\hline Scores & Group 1 (n=22) & Group 2 (n=22) & $p$ \\
\hline $\begin{array}{l}\text { Bipodal stance firm surface } \\
\text { (number of errors, median, IQR) }\end{array}$ & $0(0)$ & $0(0.5)$ & NS \\
$\begin{array}{l}\text { Bipodal stance, foam surface } \\
\text { (number of errors, median, IQR) }\end{array}$ & $0(0.37)$ & $0.75(1.5)$ & 0.008 \\
$\begin{array}{l}\text { Unipodal stance, firm surface } \\
\text { (number of errors, median, IQR) }\end{array}$ & $3(0.88)$ & $3.5(1)$ & NS \\
$\begin{array}{l}\text { Unipodal stance, foam surface } \\
\text { (number of errors, median, IQR) }\end{array}$ & $4(1.5)$ & $4(2)$ & NS \\
$\begin{array}{l}\text { Tandem stance, firm surface } \\
\text { (number of errors, median, IQR) }\end{array}$ & $2(0.88)$ & $2(1)$ & NS \\
$\begin{array}{l}\text { Tandem stance, foam surface } \\
\text { (number of errors, median, IQR) }\end{array}$ & $3(2.5)$ & $4(1)$ & 0.005 \\
$\begin{array}{l}\text { Total BESS score } \\
\text { (number of errors, mean } \pm S D)\end{array}$ & $9.87 \pm 1.6$ & $15.48 \pm 2.24$ & $<0.001$ \\
\hline
\end{tabular}




\section{Discussion}

The main aim of our study was to assess the static balance performance of healthy young individuals according to their physical activity level. Static balance performance was evaluated using the BESS test in sedentary and physical active young individuals.

Balance performance can be evaluated using a series of clinical tests or computerized force platforms systems. Systems like posturography (static or dynamic) or wearable inertial sensors provide precise data about centre of mass position and sway, information about sensory and motor postural control [20-22]. Unfortunately, these systems are very expensive and used with great difficulty in daily clinical practice. Clinical balance tests provide clinicians sufficient information in order to identify balance deficits.

BESS is a relatively easy-to-administer, rapid test that can be used for screening, monitoring, and identifying static balance deficits [23]. BESS has a moderate to good reliability $[24,25]$ and a good to high content validity in identifying balance deficits in concussed, fatigued and aging individuals, and also in ankle instabilities [26-29]. In the present study, the average of three BESS trials was used, as this was showed to increase the reliability, not only in BESS case, but also in other balance tests $[25,30]$.

The results of current study showed that sedentary young adults had a significantly greater BESS score than physically active young people. The results of the present study are in accordance with previous studies. A better balance was found in active healthy young individuals when compared to the sedentary ones.

Previous studies have shown the beneficial effects of physical activity on balance in elderly [31,32], after ankle instabilities or fractures [1] or on the quality of life in people with chronic diseases [33, 34]. The effects of physical exercises on postural balance have been investigated by
Jakobsen et al. They found an improvement in postural control after 12 weeks of training [35].

No gender differences were found in this study. Torres et al found a weak balance in sedentary men and no differences between sexes in physically active adults [36]. Height was the only anthropometrical measure that was correlated with BESS score in group 1. Same results were found in past studies [37, 38].

The current work has some limitations. The static balance was the only one evaluated. Thus, the effects of physical activity on the dynamic balance could not be investigated. The relative small number of participants is another limitation. Further studies are needed to assess the impact of different levels of physical activity on both static and dynamic balance across the lifespan.

\section{Conclusions}

The results of the present study showed that physically active young people had significantly better postural balance than sedentary ones. These results expand the previous data, sustaining the overall benefits of physical activity on the health status by reducing the impact of a majority of lifestyle diseases and improving the postural balance. We found no gender-specific differences independent of the physical activity level.

\section{Highlights}

Physical activity has beneficial effects on balance performance.

\section{Funding}

No funding was received for this study.

\section{Conflict of interest}

The authors declare no conflict of interest.

\section{References}

1. GribblePA,HertelJ,PliskyP.Using the StarExcursion Balance TesttoAssessDynamicPostural-ControlDeficitsandOutcomes in Lower Extremity Injury: A Literature and Systematic Review. Journal of Athletic Training, 2012;47:339-57. https://doi.org/10.4085/1062-6050-47.3.08.

2. Winter DA, Patla a E, Frank JS. Assessment of balance control in humans. Med Prog Technol. 1990;16: 31-51. https://doi.org/10.3138/ptc.42.2.089

3. Kiss R, Schedler S, Muehlbauer T. Associations Between Types of Balance Performance in Healthy Individuals Across the Lifespan: A Systematic Review and Meta-Analysis. Front Physiol, 2018;9:1366. https://doi.org/10.3389/fphys.2018.01366

4. Butler RJ, Lehr ME, Fink ML, Kiesel KB, Plisky PJ. Dynamic Balance Performance and Noncontact Lower Extremity Injury in College Football Players: An Initial Study. Sports Health. 2013;5: 417-422. https://doi.org/10.1177/1941738113498703

5. Onofrei R-R, Amaricai E, Petroman R, Surducan D, Suciu O. Preseason Dynamic Balance Performance in Healthy Elite Male Soccer Players. Am J Mens Health. 2019;13: 155798831983192. https://doi.org/10.1177/1557988319831920
6. Amăricăi E, Suciu O, Onofrei RR, Iacob ER, Iacob D, Popoiu $\mathrm{CM}$, et al. Static plantar pressure and functional capacity in children with femoral shaft fractures treated by titanium elastic nailing. BMC Musculoskelet Disord. 2019;20: 565. https://doi.org/10.1186/s12891-019-2951-z

7. Skelton DA. Effects of physical activity on postural stability. Age Ageing. 2001;30: 33-39. https://doi.org/10.1093/ageing/30.suppl_3.33

8. Chiriac VD, Craina ML, Stelea L, Onofrei RR, Radu D, Stoian D, et al. Physical Activity Level and Functional Status in Postmenopausal Women with Knee Osteoarthritis. In: Anastasiu D, Craina M, Hudita D, Russu M, editors. The XV Conference of the Romanian-German Society of Obstetrics and Gynecology, Timisoara, 6-8 June 2019. Timisoara: Filodiritto Publisher - International Proceedings; 2019. P. 542-545.

9. Sîrbu E, Buzaş R, Mihăescu R, Suceava I, Lighezan D. Influence of exercise training and eating behavior on arterial stiffness in young healthy students. Wien Klin Wochenschr. 2015;127: 555-560. https://doi.org/10.1007/s00508-015-0799-2

10.Sîrbu E, Pantea C, Gligor S. Social implications of nutritional status and consequences on cardiovascular risk disease 
among undergraduate trained students. Rev Cercet si Interv Soc. 2014;45: 121-131.

11.Garber CE, Blissmer B, Deschenes MR, Franklin BA, Lamonte MJ, Lee IM, et al. Quantity and quality of exercise for developing and maintaining cardiorespiratory, musculoskeletal, and neuromotor fitness in apparently healthy adults: Guidance for prescribing exercise. Med Sci Sports Exerc. 2011;43: 1334-1359. https://doi.org/10.1249/MSS.0b013e318213fefb

12.Unick JL, Lang W, Tate DF, Bond DS, Espeland MA, Wing RR. Objective Estimates of Physical Activity and Sedentary Time among Young Adults. Journal of Obesity, 2017;2017:1-11. https://doi.org/10.1155/2017/9257564

13.Sas IT, Banu A, Nicolae N, Bagiu R, Bagiu I, Mladinescu $\mathrm{CF}$, et al. Particularities of the level of physical activity performed by adolescents. Rev Chim. 2018;69: 1023-1025.

14.Štefan L, Sporiš G, Krističević T. Are lower levels of physical activity and self-rated fitness associated with higher levels of psychological distress in Croatian young adults? A cross-sectional study. PeerJ, 2018;6:e4700. https://doi.org/10.7717/peerj.4700

15.Bagiu I, Putnoky S, Tuță-Sas I, Miloicov CB, Popa M, Vlaicu B, et al. Manifestations of Self-harm in Relation with Binge Drinking to Students from Timis County, România. Rev medico-chirurgicală a Soc Medici ş̧i Nat din Iaş̧i. 2015;119: 1106-1112.

16.van Melick N, Meddeler BM, Hoogeboom TJ, Nijhuis-van der Sanden MWG, van Cingel REH. How to determine leg dominance: The agreement between self-reported and observed performance in healthy adults. PLoS One. 2017;12. https://doi.org/10.1371/journal.pone.0189876

17.Mahboubi Anarjan $\mathrm{P}$, Monfared $\mathrm{HH}$, Arslan NB, Kazak C, Bikas R. ( E )-4-Hydroxy- N '-(2-hydroxy-5iodobenzylidene)benzohydrazide methanol monosolvate. Acta Crystallogr E Struct Rep Online, 2012;68:02698-o2698. https://doi.org/10.1107/S1600536812034848

18.IPAQ Group. International Physical Activity Questionnaire Long Last 7 Days SelfAdministered Format. In: IPAQ Website. 2002. https://doi.org/10.1186/s12889-016-3778-2

19.Riemann BL, Guskiewicz KM, Shields EW. Relationship between Clinical and Forceplate Measures of Postural Stability. $J$ Sport Rehabil. 1999;8: 71-82. https://doi.org/10.1123/jsr.8.2.71

20.Mancini M, Horak FB. The relevance of clinical balance assessment tools to differentiate balance deficits. Eur J Phys Rehabil Med. 2010;46: 239-248.

21.Virag I, Stoicu-Tivadar L, Amaricai E. Browser-based medical visualization system. SACI 2014 - 9th IEEE International Symposium on Applied Computational Intelligence and Informatics, Proceedings. 2014. P. 355-359. https://doi.org/10.1109/SACI.2014.6840092

22.Muşat A, Popa Z, Craina M-L, Onofrei R, Ramona, Luca $\mathrm{CT}$, et al. Identification Of Postural Changes During Pregnancy By Using Baropodometry - Case Presentation. In: Anastasiu D, Craina M, Hudita D, Russu M, editors. The XV Conference of the Romanian-German Society of Obstetrics and Gynecology, Timisoara, 6-8 June 2019. Timisoara: Filodiritto Publisher - International Proceedings; 2019. P. 329-332.

23.IversonGL,KoehleMS.Normativedataforthemodifiedbalance error scoring system in adults. Brain Inj. 2013;27: 569-599. https://doi.org/10.3109/02699052.2013.772237

24.Bell DR, Guskiewicz KM, Clark MA, Padua DA. Systematic review of the balance error scoring system. Sports Health. 2011;3: 287-295. https://doi.org/10.1177/1941738111403122

25.Broglio SP, Zhu W, Sopiarz K, Park Y. Generalizability theory analysis of balance error scoring system reliability in healthy young adults. J Athl Train. 2009;44: 497-502. https://doi.org/10.4085/1062-6050-44.5.497

26.Docherty CL, Valovich McLeod TC, Shultz SJ. Postural control deficits in participants with functional ankle instability as measured by the balance error scoring system. Clin J Sport Med. 2006;16: 203-208. https://doi.org/10.1097/00042752-200605000-00003

27.Erkmen N, Takin H, Kaplan T, SanioluA. The effect of fatiguing exercise on balance performance as measured by the balance error scoring system. Isokinet Exerc Sci. 2009;17: 121-127. https://doi.org/10.3233/IES-2009-0343

28.Guskiewicz KM, Ross SE, Marshall SW. Postural Stability and Neuropsychological Deficits After Concussion in Collegiate Athletes. J Athl Train. 2001;36: 263-273.

29.McCrea M, Guskiewicz KM, Marshall SW, Barr W, Randolph C, Cantu RC, et al.Acute Effects and Recovery Time Following Concussion in Collegiate Football Players: The NCAA Concussion Study. J Am Med Assoc. 2003;290: 2556-2563. https://doi.org/10.1001/jama.290.19.2556

30.Onofrei RR, Amaricai E, Petroman R, Suciu O. Relative and absolute within-session reliability of the modified Star Excursion Balance Test in healthy elite athletes. PeerJ. 2019;7: e6999. https://doi.org/10.7717/peerj.6999

31.Daniel FDNR, Vale R, Giani T, Bacellar S, Dantas E. Effects of a physical activity program on static balance and functional autonomy in elderly women. Maced JMed Sci. 2010;3:21-26. https://doi.org/10.3889/MJMS.1857-5773.2010.0083

32.Mann L, Kleinpaul JF, Mota CB, Santos SG dos. Equilíbrio corporal e exercícios físicos: uma revisão sistemática TT Corporal balance and physical exercises: a systematic review. Mot rev educ fis. 2009; 15: 713-722.

33. Nemes D, Catan L, Poenaru D, Dragoi M, Amaricai E, Popa $\mathrm{D}$, et al. Life quality in patients with type III ankylosing spondylitis and secondary seronegative spondylarthropathies. Proceedings of 6th World Congress of the InternationalSociety-of-Physical-and-Rehabilitation-Medicine (ISPRM). Edizioni Minerva Medica; 2011. P. 9-11.

34.Amaricai E, Poenaru D V. The post-stroke depression and its impact on functioning in young and adult stroke patients of a rehabilitation unit. J Ment Heal. 2016;25: 137-141. https://doi.org/10.3109/09638237.2015.1022251

35.Jakobsen MD, Sundstrup E, Krustrup P, Aagaard P. The effect of recreational soccer training and running on postural balance in untrained men. Eur J Appl Physiol. 2011;111: 521-530. https://doi.org/10.1007/s00421-010-1669-2

36.Torres SF, Reis JG, Abreu DCC de. Influence of gender and physical exercise on balance of healthy young adults. Fisioter em Mov. 2014;27. https://doi.org/10.1590/0103-5150.027.003.ao10

37.Greve JMDA, Cuğ M, Dülgeroğlu D, Brech GC, Alonso AC. Relationship between anthropometric factors, gender, and balance under unstable conditions in young adults. Biomed Res Int. 2013; 850424. https://doi.org/10.1155/2013/850424

38.Alonso A, Luna N, Mochizuki L, Barbieri F, Santos S, D'Andreia Greve J. The influence of anthropometric factors on postural balance: the relationship between body composition and posturographic measurements in young adults. Clinics. 2012;67: 1433-1441. https://doi.org/10.6061/clinics/2012(12)14 


\section{Information about the authors:}

Radu Petroman; http://orcid.org/0000-0002-0574-2201; petromanradu@yahoo.com; Department of Rehabilitation, Physical Medicine and Rheumatology, "Victor Babes" University of Medicine and Pharmacy Timisoara; Piața Eftimie Murgu 2, Timișoara, 300041, Romania.

Andreea Luciana Rață; (Corresponding author); http://orcid.org/0000-0003-4009-2248; rataandreealuciana@gmail.com; Department of Vascular Surgery, "Victor Babes" University of Medicine and Pharmacy Timisoara; Piața Eftimie Murgu 2, Timișoara, 300041, Romania.

Cite this article as:

Radu Petroman, Andreea Luciana Rață. Balance performance in sedentary and active healthy young individuals - a crosssectional study. Physical education of students, 2020;24(2):115-119.

https://doi.org/10.15561/20755279.2020.0207

This is an Open Access article distributed under the terms of the Creative Commons Attribution License, which permits unrestricted use, distribution, and reproduction in any medium, provided the original work is properly cited http://creativecommons.org/licenses/by/4.0/deed.en

Received: 18.02.2020

Accepted: 28.03.2020; Published: 30.04.2020 